\title{
Associations of Body Composition with Hypertension in the Case of Geography and Health and Physical Education Teachers
}

\author{
Awoke Tibebu ${ }^{1}$ Mesenbet Aschalew ${ }^{1}$ Birhanu anjetie ${ }^{2}$ \\ 1.Author, Department of sport science, DebreMarkos university PO box 269 DebreMarkos , Ethiopia
}

\begin{abstract}
This study investigates A Comparative study between blood pressure and body composition of Geography and Health and Physical education teachers of Ginbot 20 General Secondary and Preparatory School. Furthermore, it was not very clear how blood pressure was affected by such factors as body mass index, waist circumference, waist-to-hip ratio and percent body fat. To this end the hypotheses were formulated questionnaires and experimental testing. The descriptive research design with purposive sampling techniques was used. Thereafter, a sample of 107 subjects representing 14 (13\%) of the targeted population was purposely selected for the study. The digital blood pressure monitor Measurement Machine (stethoscope), digital weight and height machine, Sphygmomanometer were used to collect data on blood pressure and body composition. Major findings of the study revealed that: Relationship between systolic and diastolic blood pressures was positively significant among the active and inactive subjects in this study; Relationship between systolic blood pressure and body mass index was positively significant among the Geography and Health and Physical Education teachers in this study; Relationship between diastolic blood pressure and body mass index was positively significant among physical exercise active and physical exercise inactive teachers .
\end{abstract}

Keywords:-Blood Pressure, Body Composition, body mass index, diastolic, systolic

DOI: $10.7176 / \mathrm{JMPB} / 65-01$

Publication date: April $30^{\text {th }} 2020$

\section{INTRODUCTION}

The prevalence of non-communicable diseases and its morbidity and mortality rates in developing countries are rapidly increasing, because of epidemiologic, demographic, and nutrition transitions. According to the World Health Report 2004, in $200229.3 \%$ of the world's mortality was due to CVD [1]. $62 \%$ of those deaths occurred in developing countries and by 2025 , the mortality rate will increased up to $75 \%$ of deaths are expected to occur in these nations $[1,2]$.Hypertension represents a major public health challenge as it is considered to be the leading risk factor for cardiovascular mortality and accounts for a large proportion of premature deaths worldwide,[3] which kills more than nine million people per year globally.[4]Hypertension is a risk factor for stroke, coronary heart disease, heart failure and chronic renal failure and its global importance is recognized, particularly in the context of increasing obesity.[5-7] Obesity is also linked to other chronic diseases and metabolic disorders. [8] Several studies have showed that overweight is one of the principal factors related to increased incidence of hypertension in worldwide [9-11]. Overweight and obesity increase the risks of high BP, coronary heart disease, ischemic stroke, type II diabetes mellitus and certain cancers. Worldwide about $58 \%$ of diabetes mellitus and $21 \%$ of ischemic heart disease are attributable to BMI above $21 \mathrm{~kg} / \mathrm{m}^{2} \cdot[12,13] \mathrm{In}$ recent years, emerging data have suggested that abdominal obesity is a more important risk factor for cardiovascular and metabolic diseases than is general obesity. [14,15] Cross sectional and observational studies have documented a positive association between blood pressure and body weight $(16,17)$ and blood pressure increases over time among subjects who experience weight gain. [18] Increased BMI is associated with increased systolic blood pressure, which in turn is associated with increased vascular mortality.[19] Studies showed that the incidence of fat accumulation due to inactive lifestyle and other tendencies such as positive energy balance and excessive gestational weight gain affect quality of life with serious health implications.[20,21] The benefits of regular PA are substantial as it plays a crucial role in the regulation and maintenance of an adolescent's body weight by decreasing the percentage body fat.[22]

\section{Statement of the Problem}

This study designed to Comparative Study of Blood pressure and body compositions between Geography and Health and Physical Education teachers in Ginbot 20 Secondary and Preparatory School.Physical fitness is the general ability to take and respond favorably to physical effort. Wellness is the search for enhanced quality of life, personal growth, and potential through positive lifestyle behaviors and attitudes. Movement and physical activity are basic functions for which human organism was created.

There are many studies [24-27] that show the significant relationship of body composition and blood pressure with age, physical inactivity and eating habits. "Blood pressure" signifies the resistance produced each time the heart beats and sends blood coursing through the arteries. The peak pressure exerted by this contraction is the systolic pressure. Between beats, the heart relaxes, and blood pressure drops. The lowest pressure is referred to as the diastolic pressure. A normal blood pressure reading for an adult is: 120 (systolic) / 80 
(diastolic). High blood pressure is divided into different levels.

- Borderline (120-160/90-94)

- Mild (140-160/95-104)

- Moderate 140-180/105-114)

- Severe $(160+/ 115+)$

There are several factors associated with the incidence of high blood pressure. Some of these factors like heredity, family background, age and sex. There are factors that are modifiable like diet, exercise, sleep, consumption of fatty diet, obesity, overweight and cigarette smoking. Exercise physiologists attempt to use different forms of exercise as an intervention to prevent the incidence of overweight and obesity. This investigation was therefore conducted to A Comparative Study of Blood Pressure and Body Composition between Geography and Physical education Teachers of Ginbot 20 General Secondary and Preparatory School.

Research Questions

This investigation was designed to answer the following questions:

* What is the relationship between blood pressure and body composition of Health and Physical Education Teachers?

* What is the relationship between blood pressure and body composition of Geography Teachers?

* What is the relationship between blood pressure and Body Composition of Geography and Physical Education teachers?

\section{Objectives of the Study}

General Objective

The purpose of this study was to determine the relationship between body composition and blood pressurebetween geography and health and physical education teachers of Ginbot 20 General secondary and preparatory School.

Specific Objectives

The Study has the following specific objectives:-

\# To examine blood pressure and body composition status of geography teachers of Ginbot 20 Secondary and Preparatory School.

* To rate blood pressure and body composition status of Health and Physical Education teachers of Ginbot 20 Secondary and Preparatory School.

* To analysis blood pressure and body composition geography teachers of Ginbot 20 Secondary and Preparatory School.

\section{RESEARCH METHODOLOGY}

\section{Research Design}

A cross sectional descriptive study design with qualitative and quantitative approaches was employed in this study. In order to assess A comparative study of blood pressure and body composition between Geography and Health and Physical Education Teachers of Ginbot 20 General secondary and preparatory School quantitative method was used the information which was collected from questionnaires, and scientific measurements (stethoscope, sphygmomanometer, digital weight machine, height measurement machine) to present in percentage and tables.

\section{Source of Data}

The researcher used both primary and secondary source of data. In order to realize the objective of the study and adequately answer the research questions, data were gathered from both primary and secondary sources of information. Additionally, intensive review of related literatures was made to support the study with empirical knowledge in the area.

A. Primary Source of Data: -Experimental testing: was employed to generate quantitative data relevant from the target population. There were 6 Health and Physical education teachers and 8 Geography teachers total 14 target populations involved in this experimental testing.

B. Secondary Source of Data:- The secondary sources of information were obtained from different related researches ,from Lumamie Primary Hospital patients documents and from the Hospital Nurse .

\section{Population of the Study}

The participants of this study are Ginbot 20 General Secondary and Preparatory School Health and Physical Education Teachers and Geography teachers. Since the study was expected to investigate answers for the above mentioned topic, it assumes that it would be quite appropriate to get the relevant data directly from the target population. The target population included 91 male and 16 female totals of 107 teachers working in Ginbot 20 General Secondary and preparatory school in 2010 E.C. Among them 7male and 1 female total 8 Geography teachers, 5 male and 1 female total 6 health and physical education teachers participated in the experimental testing by selected purposive sampling. Educational qualification of all 16 percipients is degree and above. The data were collected on a comparative study of blood pressure and body composition on Ginbot 20 General 
Secondary School of Geography and Health and Physical Education teachers.

\section{Sample Size and Sampling Techniques}

The sample size of the study was determined by target population about 107 Ginbot 20 General and Secondary School teachers. The researcher had selected 7 male and 1 female total 8 Geography teachers, 5 male and 1 female total 6 health and physical education teachers participated. From 8 Geography teachers $8(100 \%)$ are participated and from total of 6 health and physical education teachers $6(100 \%)$ teachers are participated. In order to select sample from the target population, the researcher adapted purposive sampling strategies to participate in the questionnaires and experimental testing. Purposive sampling used to collect concret evidences for measuring blood pressure and body composition of the participants. The target population of geography and health and physical education teachers all of 12 male and 2 female total of $14(100 \%)$ teachers were participated. To measure the blood pressure stethoscope and sphygmomanometer, skin-fold caliper was used to measure the body fat and digital weighing machine was used to measure the body weight.

\section{Data Collection Tools}

The data was collected on blood pressure and body composition of Ginbot 20 General Secondary and Preparatory School Geography, Health and Physical Education Teachers. To measure the blood pressure the researcher used Stethoscope and sphygmomanometer. Also used digital weighing machine used to measure the participant's bodyweight.

Questionnaire:- was employed to generate both qualitative and quantitative data relevant to the demographic, social and economic characteristics of the sample population. For this purpose, the questionnaire was designed comprising of close-ended and open ended questions. There were 14 respondents involved in this questionnaire. The questionnaire was also prepared in English language the researcher expected to understand the concept of questionnaires because of they are in degree and masters level. Out of the total questionnaires distributed to the target population, all (100\%) i.e. 12 male respondents and 2 female respondents were returned.

The researcher used questionnaires because of the following reasons:-

$>$ It allows enough time to think.

$>$ It gives freedom for the respondents.

$>$ It enables to collect truth information about the problem.

Experimental testing: was employed to generate quantitative data relevant from the target population. There were 14 target populations involved in this experimental testing. In the experimental test the researcher used stethoscope and sphygmomanometer.

\section{Data Collection Procedures}

In this research investigated a comparative study of blood pressure and body composition between Geography and Health and Physical Education Teachers of Ginbot 20 General Secondary and Preparatory school. Close ended questionnaires were prepared and distributed the respondents to select their answers as a form of to choose best answer. In the experimental testing the researcher Measure respondents weight, height, body fat, blood pressure and body composition by using scientific instruments in stethoscope, sphygmomanometer, digital weight machine, , height measurement machine.

\section{Blood Pressure Measurement Procedures}

A fully automated blood pressure monitor using digital sphygmomanometer method was used (Omron Automatic Digital Blood Pressure Monitor (endorsed by the American Heart Association, model no. HEM 713C. Blood pressure was recorded in $\mathrm{mmHg}$ from the patients' arm, in sitting position. Measurements were taken twice and a mean value was computed. Hypertension was defined by a systolic $\mathrm{BP} \geq 140 \mathrm{mmHg}$ and/or, diastolic $\mathrm{BP} \geq 90 \mathrm{mmHg}$

\section{Anthropometry and body composition}

Body weight, and height, was measured using standard methods. [23] Weight was measured on subjects dressed in their normal underclothes with no shoes or objects in their pockets. The measure was taken using a digital scale with a precision of 100 grams. Height was measured to the nearest $0.1 \mathrm{~cm}$; with the subjects bare footed, standing with their backs to a stadiometer. All measurements were done twice. If the difference between the two first measurements was greater than $0.5 \mathrm{~kg}$ for body weight, $1.0 \mathrm{~cm}$ for height, a third measurement was done and the two closest measurements were used. The mean of each measure was calculated. BMI was computed as weight $(\mathrm{kg})$ divided by height squared $\left(\mathrm{m}^{2}\right)$. Overweight was defined as a BMI between 25.0 and 29.9 and obesity as a BMI equal or greater than $30.0 \mathrm{~kg} / \mathrm{m}^{2}$.

\section{Data Analysis Techniques}

The collected data from different sources by using different instruments were classified, organized, and interpreted by using descriptive statistics such as tables and percentages to give a digested picture of the data. Accordingly, the summarized data from the structured questionnaire were analyzed in line with the theoretical frame work and the objective of the research to arrive at a meaningful conclusion. In similar ways, information generated from scientific measurements was analyzed by using quantitative techniques. 


\section{Results}

\section{Demographic characteristics of the Respondents}

Based on the responses obtained from Ginbot 20 General Secondary And preparatory School Geography and Health and Physical Education Teachers. The characteristics of the study groups were examined in terms of their sex, age, marital status, and educational qualification.

Table 4.1 Background Characteristics of the Respondent

\begin{tabular}{|c|c|c|c|c|c|c|c|c|}
\hline \multirow[t]{2}{*}{ No } & \multirow{2}{*}{\multicolumn{2}{|c|}{ Variable }} & \multicolumn{3}{|c|}{ Geography Teachers } & \multicolumn{3}{|c|}{ HPE Teachers } \\
\hline & & & $\mathrm{M}$ & $\mathrm{F}$ & $\mathrm{T}$ & $\mathrm{M}$ & $\mathrm{F}$ & $\mathrm{T}$ \\
\hline \multirow[t]{2}{*}{1.} & \multirow[t]{2}{*}{ Gender } & $\mathrm{M}$ & 7 & 1 & 8 & 5 & 1 & 6 \\
\hline & & $\mathrm{F}$ & 1 & 1 & - & 1 & - & - \\
\hline \multirow[t]{4}{*}{2.} & \multirow[t]{4}{*}{ Age } & $20-25$ & - & - & - & 1 & - & 1 \\
\hline & & $26-30$ & 3 & 1 & 4 & 3 & 1 & 4 \\
\hline & & $31-35$ & 3 & - & 3 & 1 & - & 1 \\
\hline & & Above 35 & 1 & - & 1 & - & - & - \\
\hline \multirow[t]{3}{*}{3.} & \multirow[t]{3}{*}{ Marital Status } & Single & 1 & - & 1 & 3 & 1 & 4 \\
\hline & & Married & 6 & 1 & 7 & 2 & - & 2 \\
\hline & & Divorce & - & - & - & - & - & - \\
\hline \multirow[t]{3}{*}{4.} & \multirow[t]{3}{*}{ Educational Status } & Diploma & - & - & - & - & - & - \\
\hline & & Degree & 4 & 1 & 5 & 5 & 1 & 6 \\
\hline & & Masters & 3 & - & 3 & - & - & - \\
\hline
\end{tabular}

NB: $M=$ Males, $F=$ Females, $T=$ Total

Based on the above table the following evidences are occurred .From 8 Geography teachers, $7(87.5 \%)$ are male teachers, 1(12.5\%) was female teacher. From 6 Health and Physical Education teachers 5(83.3\%) were male teachers and $1(16.7 \%)$ of the female teacher. Age level of the respondents $3(37.5 \%)$ male and $1(12.5 \%)$ female teachers were between 26-30 years old, 3(37.5\%) were between 31-35 years old, 1(12.5\%) of them above 35 years old. Age level of health and physical education teachers 1 (16.7\%) male teacher was between 20-25 years old, $3(50 \%)$ males and 1(16.7\%) female teachers found between 26-30 years old and 3(50\%) male teachers found between 31-35 years old.

Marital Status of the respondents are as follows.1 (12.5\%) male Geography teacher was single, 6(75\%) males and 1(12.5\%) female Geography teachers were married. Health and Physical Education teachers 3(37.5\%) males and 1(16.7\%) female teachers were single, 2(33.3\%) male teachers were married.

Educational Qualification of the respondents was the following. Educational qualification of Geography teachers were, 4(50\%) male and 1(12.5\%) female teachers have Bachelor's Degree qualification, 3(37.5\%) male teachers were Master's Degree Educational level. Educational level of Health and Physical Education teachers were, 5(83.3\%) male and 1(16.7\%) female teachers have Degree educational Qualification.

Based on the above data Most of Geography and Health and Physical teachers were males, 7(87.5\%) Geography and $5(83.3 \%)$ health and physical education teachers were males. Most of Geography teachers, $4(50 \%)$ and 4(66.7) health and physical education teachers found between 26-30 years old.6 (75\%) Geography teachers were married, $4(66.7 \%)$ health and physical education teachers were single. Educational Qualification of Geography teachers were, 5(62.5\%) Degree and 6(100\%) health and physical Education teachers have Bachelor Degree.

\section{Results of Blood Pressure}

Stethoscope is a medical instrument used for listening to sounds produced within the body, often combined with a sphygmomanometer. The researcher used blood pressure apparatus stethoscope ,product of America,model No 15578 .Based on the instrument result the healthy person should expressed 120 systolic and 80 diastolic. The screen displayed the systolic, and diastolic blood pressures, and the heart rate (in beats per minute). The blood pressure of every subject was subsequently recorded in the Raw Data Sheet. For each subject, two measurements were taken on the right arm with at least a minute interval and the average of the readings was recorded; systolic pressure over diastolic pressure in millimeters of mercury.

Table 4.3.1 measurement of blood pressure

\begin{tabular}{|l|l|l|l|l|l|l|l|l|l|l|l|l|}
\hline No & Testing & \multicolumn{3}{l|}{ Geography Teachers } & \multicolumn{3}{l|}{ HPE teachers } & \multirow{2}{*}{ Total) } & \multirow{2}{*}{ Percent (\%) } \\
\cline { 4 - 12 } & & M & F & T & $\%$ & M & F & T & & & \\
\hline 1. & Measurement of Blood & & & & & & & & & & \\
& Pressure & & & & & & & & & & \\
& A.120/80 & 2 & - & 2 & 25 & 5 & - & 5 & 83.3 & 7 & 50 \\
& B. Above 120/80 & 3 & 1 & 4 & 50 & - & 1 & 1 & 16.7 & 5 & 35.7 \\
& C. Below 120/80 & 2 & - & 2 & 25 & - & - & - & & 2 & 14.2 \\
\hline
\end{tabular}


Based on table 4.3.1, 2(25\%) Geography teachers should have 120millimeters of mercury (mm $\mathrm{Hg}$, (systolic: $16 \mathrm{kpa})$ and 80 millimeters of mercury $(\mathrm{mm} \mathrm{Hg})$ (diastolic:10kpa). But mean value of $4(50 \%)$ Geography teachers expressed the laboratory test show that above 120/80 means that 125.5/85.5millimeters of mercury (mm Hg), 2(25\%) Geography teachers blood pressure show that they have below 120/80(systolic and diastolic i.e. 117.5/77.5millimeters of mercury ( $\mathrm{mm} \mathrm{Hg}$ ) .

The Blood pressure of Health and Physical Education teachers also measured by the blood pressure Stethoscope. The mean value shows that 5(83.3\%) teachers result expressed that their systolic and diastolic relation was $120 / 80,1(16.7 \%)$ millimeters of mercury $(\mathrm{mm} \mathrm{Hg})$ shows that the teacher has above $120 / 80$ it was 123/83 millimeters of mercury ( $\mathrm{mm} \mathrm{Hg}),(123$ systolic and 83 diastolic).

From all participants the test shows that, 7(50\%) respondents blood pressure shows that they have 120/80(120 systolic, 80 diastolic)( systolic 16kpa,diastolic 10kpa),5(35.7\%) respondents blood pressure expressed above $120 / 80$ the mean value shows that $124 / 84$ millimeters of mercury (mm $\mathrm{Hg}) .2(14.2 \%)$ respondents blood pressure mean value showed that they have below 120/80 it was 117/77millimeters of mercury $(\mathrm{mm} \mathrm{Hg})$. We concluded that blood pressure has direct relationship with the daily physical exercise. An individual conducted physical exercise to create normal blood pressure it was 120/80 systolic and diastolic. It also affected the health of these teachers.

\section{Results of Body Mass Index}

Weight and height were measured separately and used to determine the body mass Index. The body weight of the target samples were measured in light indoor clothing, without shoes, overcoat, hat, hair braids, or handsets using a bathroom weighing scale. Body mass index (BMI) was determined by dividing weight (wt) in kilogram's $(\mathrm{kg})$ by height $(\mathrm{ht})$ in square meter $\left(\mathrm{m}^{2}\right)$ as in the following formula:-

$$
\mathrm{BMI}=\mathrm{wt}(\mathrm{kg}) / \mathrm{ht}\left(\mathrm{m}^{2}\right)
$$

Table 4.3.2.1 Body Mass Index (BMI) of Geography Teachers

\begin{tabular}{|l|l|l|l|l|l|}
\hline No & Subjects & Sex & Weight & Height & BMI( Body Mass Index \\
\hline 1 & Respondent One & F & $67 \mathrm{~kg}$ & $1.55 \mathrm{~m}$ & $67 \mathrm{~kg} / 2.4 \mathrm{~m}^{2}=27.9 \mathrm{~kg} / \mathrm{m}^{2}$ \\
\hline 2 & Respondent Two & M & $62 \mathrm{~kg}$ & $1.53 \mathrm{~m}$ & $62 \mathrm{~kg} / 2.3 \mathrm{~m}^{2}=26.9 \mathrm{~kg} / \mathrm{m}^{2}$ \\
\hline 3 & Respondent Three & M & $65 \mathrm{~kg}$ & $1.67 \mathrm{~m}$ & $65 \mathrm{~kg} / 2.7 \mathrm{~m}^{2}=23.2 \mathrm{~kg} / \mathrm{m}^{2}$ \\
\hline 4 & Respondent Fourth & M & $68 \mathrm{~kg}$ & $1.59 \mathrm{~m}$ & $68 \mathrm{~kg} / 2.5 \mathrm{~m}^{2}=27.2 \mathrm{~kg} / \mathrm{m}^{2}$ \\
\hline 5 & Respondent Five & M & $70 \mathrm{~kg}$ & $1.59 \mathrm{~m}$ & $70 \mathrm{~kg} / 2.5 \mathrm{~m} 2=28 \mathrm{~kg} / \mathrm{m} 2$ \\
\hline 6 & Respondent Sixth & M & $67 \mathrm{~kg}$ & $1.56 \mathrm{~m}$ & $67 \mathrm{~kg} / 2.4 \mathrm{~m} 2=27.9 \mathrm{~kg} / \mathrm{m} 2$ \\
\hline 7 & Respondent Seventh & M & $69 \mathrm{~kg}$ & $1.62 \mathrm{~m}$ & $69 \mathrm{~kg} / 2.6 \mathrm{~m} 2=26.5 \mathrm{~kg} / \mathrm{m} 2$ \\
\hline 8 & Respondent Eight & M & $66 \mathrm{~kg}$ & $1.52 \mathrm{~m}$ & $66 \mathrm{~kg} / 2.3 \mathrm{~m} 2=28.6 \mathrm{~kg} / \mathrm{m} 2$ \\
\hline
\end{tabular}

Based on the above table from 8 total Geography teachers ,3 (37.5\%) of them has good Body Mass Index and the remaining 5(62.5\%) geography teachers has high risk Body Mass Index.

We can understand most of the geography teachers did not participated in physical exercise and affected by Obesity and health problems.

Table 4.3.2.2 Body Mass Index (BMI) of Health and Physical Education Teachers

\begin{tabular}{|l|l|l|l|l|l|}
\hline No & subjects & Sex & Weight & Height & BMI(Body Mass Index) \\
\hline 1 & Respondent one & F & $58 \mathrm{~kg}$ & $1.68 \mathrm{~m}$ & $58 \mathrm{~kg} / 2.8 \mathrm{~m} 2=20.7 \mathrm{~kg} / \mathrm{m} 2$ \\
\hline 2 & Respondent two & M & $56 \mathrm{~kg}$ & $1.70 \mathrm{~m}$ & $56 \mathrm{~kg} / 2.8 \mathrm{~m} 2=20 \mathrm{~kg} / \mathrm{m} 2$ \\
\hline 3 & Respondent three & M & $61 \mathrm{~kg}$ & $1.67 \mathrm{~m}$ & $61 \mathrm{~kg} / 2.7 \mathrm{~m} 2=21.8 \mathrm{~kg} / \mathrm{m} 2$ \\
\hline 4 & Respondent four & M & $59 \mathrm{~kg}$ & $1.59 \mathrm{~m}$ & $59 \mathrm{~kg} / 2.5 \mathrm{~m} 2=23.6 \mathrm{~kg} / \mathrm{m} 2$ \\
\hline 5 & Respondent five & M & $54 \mathrm{~kg}$ & $1.69 \mathrm{~m}$ & $54 \mathrm{~kg} / 2.8 \mathrm{~m} 2=19.2 \mathrm{~kg} / \mathrm{m} 2$ \\
\hline 6 & Respondent six & M & $64 \mathrm{~kg}$ & $1.59 \mathrm{~m}$ & $64 \mathrm{~kg} / 2.5 \mathrm{~m} 2=25.6 \mathrm{~kg} / \mathrm{m} 2$ \\
\hline
\end{tabular}

Measurement machine Digital Height and Weight machine American Model, white color 5572 model number. From the above experimental test the health and physical education teachers are participated and the results are concluded the following. From 5 male and 1 female total 8 health and physical education teachers, all $6(100 \%)$ teachers has Good Body Mass Index(BMI) .We understand that these physical education teachers actively participated in physical fitness exercises. So the participation in the physical exercise they created good relationship blood pressure and body composition.

\section{Conclusion}

Based on the results of the study, the researcher has found the following major problems, most of which are Geography teachers and Health and Physical Education teachers related, which have to be revised straight away. Based on the findings and in view of the limitations, the study therefore confirmed that:

(i) As systolic blood pressure increased, diastolic blood pressure also increased.

(ii) As body mass index increased, waist circumference and arterial blood pressure also increased. Therefore 
body mass index as a modifiable risk factor of elevated blood pressure can be the best predisposing risk factor for cardiovascular disease in the inactive group which means geography teachers

The research showed that the Geography teachers did not participated in physical exercise their blood pressure test indicated that over or under normal condition. As systolic blood pressure increased, diastolic blood pressure also increased. These two variables have direct relationship in the normal condition but the experiment showed that Geography teaches systolic and diastolic blood pressure has indirect relation.

\section{Discussion}

The assessment of the human body composition is a useful practice in various fields, including medicine, nutrition, and sports sciences.[36, 37]

We found an independent association between body mass index and BP among inactive teachers with different mean BP levels. As noted earlier, the obesity is a disorders in which contributes to the majority of noncommunicable chronic diseases $[8,12,13]$

Previous studies have similarly reported, body composition generally affects cardio respiratory performance and function.[35] Obesity is significantly associated with non-communicable disease[28-31] and is one of the main determinants of hypertension in the general population[32]. The relationships among body size and structure, performance and health are interrelated.[35] Obese people have been found to have a much higher occurrence of high blood pressure (BP)[29]. High BP was shown to be independently associated with high BMI [30] and is due to excessive fat accumulation in the heart, liver, muscle, and blood vessels [33]. Obesity increases the risk of all-cause mortality by approximately $50 \%$. It has a greater impact, however, on the risk of developing associated diseases [34].

The results of the study highlight the essential need for future researches using larger samples to examine and compare the overall factors of BMI on hypertension.

\section{References}

1. World Health Organization. The World Health Report 2004. Geneva: World Health Organization, 2004.

2. World Health Organization. The World Health Report 2002. Geneva: World Health Organization, 2002.

3. Fang,L.,Song,J.,Ma,Z.,Zhang,L.,Jing,C.,\&Chen,D.(2014).Prevalenceandcharacteristicsofhypertensioninmai nland Chinese adults over decades: A systematic review. Journal of Human Hypertension, 28,649-656.

4. World Health Organization. SECTION I: Why hypertension is a major public health issue. In: A Global Brief on Hypertension: Silent Killer, Global Public Health Crisis. Geneva, Switzerland: WHO; 2013:8-15.

5. National High Blood Pressure Education Program Working Group on High Blood Pressure in C, Adolescents (2004) The fourth report on the diagnosis, evaluation, and treatment of high blood pressure in children and adolescents. Pediatrics 114:555-576.PMID:15286277 \

6. Chen X, Wang Y (2008) Tracking of blood pressure from childhood to adulthood: a systematic review and meta-regression analysis. Circulation 117:3171-3180.doi:10.1161/CIRCULATIONAHA.107. 730366PMID:18559702

7. Emaus A, Veierød MB, Tretli S, Finstad SE, Selmer R, Furberg AS, et al. Metabolic profile, physical activity, and mortality in breast cancer patients. Breast Cancer Res Treat 2010; 121 (3): 651-660.

8. Guh DP, Zhang W, Bansback N, Amarsi Z, Birmingham CL, Anis AH. The incidence of co-morbidities related to obesity and overweight: a systematic review and meta-analysis. BMC Public Health 2009; 9: 88.

9. Kotsis V, Stabouli S, Papakatsika S, Rizos Z, Parati G. Mechanisms of obesity induced hypertension. Hypertens res off J Jpn Soc. Hypertension. 2010;33: 386-93.

10. Stepien M, Stepien A, Banach M, Wlazel RN, Paradowski M, Rizzo M, et al. New obesity indices and adipokines in normotensive patients and patients with hypertension: comparative pilot analysis. Angiology. 2014;65:333-42.

11. Sorof JM, Lai D, Turner J, Poffenbarger T, Portman RJ. Overweight, ethnicity, and the prevalence of hypertension in school-aged children. Pediatrics. 2004; 113: 475-82.

12. World Health Organization. World Health Report 2002: Reducing risks, Promoting Healthy Life. World Health Organization: Geneva, 2002.

13. Valentino, María José Bustamante, Lorena Orellana et al, Body fat and its relationship with clustering of cardiovascular risk factors Giovanna, Nutr Hosp. 2015;31(5):2253-2260 ISSN 0212-1611

14. Field AE, Cook NR, Gillman MW. Weight status in childhood as a predictor of becoming overweight or hypertensive in early adulthood. Obes Res. 2005; 13: 163-9.

15. Janssen,I.,Katzmarzyk,P.T.,\&Ross,R.(2004).Waist circumference and not body mass index explains obesity-related health risk. The American Journal of Clinical Nutrition, 79, 379-384.

16. Wilsgaard T, Schirmer H, Arnesen E. Impact of body weight on blood pressure with a focus on sex differences: the Tromsø Study, 1986-1995. Arch Intern Med 2000; 160 (18): 2847-2853. 13.

17. AinaEmaus, Tom Wilsgaard et al, Blood pressure, cardiorespiratory fitness and body mass: Results from 
the Tromsø Activity Study, NorskEpidemiologi 2011; 20 (2): 189-197

18. Kotchen TA. Obesity-related hypertension: epidemiology, pathophysiology, and clinical management. Am J Hypertens 2010; 23: 170-1178.

19. Annemarié ZEELIE, Sarah J. MOSS, H. Salome KRUGER, Johannes M. VAN ROOYEN, THE IMPACT OF A 10-WEEK PHYSICAL ACTIVITY INTERVENTION PROGRAMME ON SELECTIVE METABOLIC SYNDROME MARKERS IN BLACK ADOLESCENTS, South African Journal for Research in Sport, Physical Education and Recreation, 2010, 32(1):147-162. 2010, 32(1):147-162. ISSN: 0379-9069

20. Vendhan Gajalakshmi, Ben Lacey, Vendhan Kanimozhi et al, Body-mass index, blood pressure, and causespecific mortality in India: a prospective cohort study of 500810 adult, 2018

21. CRUZ, M.L.; HUANG, T.T.K.; JOHNSON, M.S.; GOWER, B.A. \& GORAN, M.I. (2002). Insulin sensitivity and blood pressure in black and white children. Hypertension, 40: 18-22.

22. AMERICAN COLLEGE OF SPORTS MEDICINE (ACSM) (2006). ACSM's guidelines for exercise testing and prescription (7th ed.). Philadelphia, PA: Lippincott Williams \&Wilkens.

23. Lohman T, Roche KA, Martorell R, eds. Anthropometric standardization reference manual. Champaign, IL: Human Kinetics, 1991.

24. Bakari, AG, Onyemelukwe, GC, Sani, BG, Aliyu, IS, Hassan, SS, \&Aliyu, TM, (2007). Obesity, overweight and underweight in suburban northern Nigeria. International Journal on Diabetes Metabolism 15: 68 - 69 ABU: Zaria.

25. Christensen, DL, Eis, J, Hansen, AW, Larson, MW, Mwaniki, D1, Kilonza, B, Tetens, I, Boit, MK, Kaduka, L, Borch - Johnsen, K, \&Friis, H, (2008). Obesity and regional fat distribution in Kenyan populations: Impact of ethnicity and urbanisation. Annal of Human Biology, March - April 2008; 35 (2): 232 - 249.

26. Manuel Ramírez-Zea, PaúlMelgar, Rafael Flores, et al Physical fitness, body composition, blood pressure, and blood metabolic profile among young Guatemalan adults, Food and Nutrition Bulletin, vol. 26, no. 2, 2005, The United Nations University

27. Chloe Creber, Richard S. Cooper, Jacob Plange-Rhule et al, Independent association of resting energy expenditure with blood pressure: confirmation in populations of the African diaspora, BMC Cardiovascular Disorders (2018) 18:4 DOI 10.1186/s12872-017-0737-5

28. WHO global strategy ondiet, physical activity and health. World Health Organization: Geneva; 2003.

29. Hall, J. E., J. M. do Carmo, A. A. da Silva, Z. Wang, and M. E. Hall. 2015. Obesity-induced hypertension: Interaction of neurohumoral and renal mechanisms.

30. Kotsis, V., S. Stabouli, S. Papakatsika, Z. Rizos, and G. Parati. 2010. Mechanisms of obesity induced hypertension. Hypertens Res.

31. Eurostat, 2014 Overweight and obesity - BMI statistics, Statistics Explained

32. DeMarco, V. G., A. R. Aroor, and J. R. Sowers. 2014. The pathophysiology of hypertension in patients with obesity. Nat Rev Endocrinol.

33. Kang, Y. S. 2013. Obesity associated hypertension: New insights into mechanism. Electrolyte Blood Press.

34. World Health Organization. Obesity and Overweight. 2017. Available online: http://www.who.int/en/newsroom/fact-sheets/detail/obesity-and-overweightaccessed on 10 May 2018).

35. Henry C. Lukaski, Body composition: health and performance in exercise and sport, 2017 by Taylor \& Francis Group, LLC

36. Ackland, T. R., T. G. Lohman, J. Sundgot-Borgen et al. 2012. Current status of body composition assessment in sport: Review and position statement on behalf of the ad hoc research working group on body composition health and performance, under the auspices of the I.O.C. Medical Commission. Sports Med 42:227-49.

37. Fosbøl, M. and B. Zerahn. 2015. Contemporary methods of body composition measurement. ClinPhysiolFunct Imaging 35:81-97. 